\title{
Perancangan Sistem Vertikultur Metode Nutrient Film Technique dengan Penyesuaian Arah Gerak Cahaya Matahari Berbasis Mikrokontroler
}

\author{
Ratna Cita Dewi ${ }^{1}$, Harlianto Tanudjaja ${ }^{2}$, Joni Fat ${ }^{1}$
}

\begin{abstract}
Plant cultivation in verticulture system uses the hydroponic method that is Nutrient Film Technique (NFT). NFT is a method to circulate the nutrition liquid continuously in 24 hours long to help the growth of the plant with a shorter time for the commercial plants. Usually the distribution of sunlight in verticulture system are not equal, it causes for some plants unable to photosynthesis and wither. Designing a moving verticulture system based on the sunlight direction is the main solution to solve the sunlight receiving problem to the plant. This design will include a Light Dependent Resistor (LDR) driver module, motor driver module, microcontroller module, motor movement limit detection module, nutrition liquid level detection module and power supply module. The verticulture system works on receiving sunlight by detecting a sunlight that focused on the LDRs, then processed by the microcontroller to turn on the Direct Current (DC) motor with direction and speed that have been adjust. The examination was done in an open area from morning until night. Sunlight received by the sensor will determine the direction of the verticulture. This design also has a nutrition liquid level detection sensors that connected directly to power supply. The examination was done by detecting the minimum limit from the nutrition liquid availability in the water tank. The purpose of this examination is so that the availability system of nutrition liquid inside the tank is fulfilled. The conclusion from designing a verticulture system with NFT method in receiving sunlight and control of watering nutrition liquid can make the plants grow faster then the conventional plants.
\end{abstract}

KEYWORDS: verticulture system, NFT method, sunlight.

ABSTRAK: Pembudidayaan tanaman pada sistem vertikultur menggunakan metode hidroponik yaitu Nutrient Film Technique (NFT). NFT merupakan metode sirkulasi larutan nutrisi yang dilakukan secara terus-menerus selama 24 jam untuk membantu pertumbuhan pada tanaman dengan waktu tumbuh lebih singkat dari tanaman komersial. Secara umum, pembagian cahaya pada sistem vertikultur tidak merata di setiap tingkatan sehingga mengakibatkan tanaman tidak dapat berfotosintesis dengan baik dan cenderung layu. Perancangan sistem pergerakan vertikultur berdasarkan posisi gerak cahaya matahari adalah solusi utama untuk menyelesaikan permasalahan pencahayaan matahari yang diterima oleh tanaman. Rancangan sistem ini terdiri dari modul driverLight Dependent Resistor (LDR), modul motor driver, modul mikrokontroler, modul pendeteksi batas gerak motor, modul pendeteksi batas ketinggian larutan nutrisi dan modul catu daya. Cara kerja dari sistem vertikultur untuk penerimaan cahaya matahari dilakukan dengan mendeteksi cahaya yang terfokus pada sensor LDR, kemudian diproses oleh mikrokontroler untuk menghidupkan motor Direct Current (DC) dengan arah dan kecepatan yang telah ditentukan. Pengujian sistem vertikultur dilakukan pada ruangan terbuka dengan cahaya matahari pagi hingga malam hari. Cahaya matahari yang diterima oleh sensor mempengaruhi arah gerak vertikultur. Perancangan ini juga terdapat sensor pendeteksi ketinggian larutan nutrisi yang terhubung langsung dengan catu daya. Pengujian dilakukan dengan mendeteksi batas minimum dari ketersediaan larutan nutrisi di dalam tangki. Hal ini dituju agar ketersediaan larutan nutrisi di dalam tangki tercukupi. Kesimpulan yang diperoleh dari perancangan sistem vertikultur metode NFT dalam hal penerimaan cahaya matahari dan pengendalian pengairan larutan nutrisi dapat membuat tanaman tumbuh lebih cepat dari tanaman konvensional.

KATA KUNCI: sistem vertikultur, metode NFT, cahaya matahari.

\section{PENDAHULUAN}

$\mathrm{T}_{\mathrm{j}}^{\mathrm{a}}$ anaman adalah makhluk hidup yang dapat tumbuh dan berkembang. Tanaman dapat tumbuh dan berkembang jika mendapatkan cahaya matahari yang cukup untuk proses fotosintesis dan pengontrolan nutrisi yang sesuai dengan kebutuhan tanaman. Nutrisi-nutrisi yang dibutuhkan oleh tanaman dapat diperoleh dari tanah yang memiliki mineral atau yang diberikan oleh manusia secara langsung. Nutrisi yang didapat dari tanah belum tentu baik bagi pertumbuhan serta penerimaan cahaya matahari pada tanaman sehingga dibutuhkan teknik untuk mengontrol pertumbuhan dari tanaman.

Teknik vertikultur merupakan salah satu teknik pembudidayaan tanaman yang dapat membantu pertumbuhan tanaman. Vertikutur berasal dari kata vertical dan culture yang berarti sistem budidaya tanaman yang dilakukan secara vertical atau bertingkat, baik indoor mau pun outdoor. Sistem budidaya vertikultur cocok untuk penghijauan di daerah perkotaan maupun daerah yang mempunyai lahan yang terbatas. Teknik vertikultur ini dapat di tempatkan pada perkarangan rumah yang cocok untuk pehobi dan pencinta tanaman sehingga vertikultur ini dapat direalisasikan dalam skala rumah tangga.

Penempatan vertikultur ini sangat berguna untuk penanaman yang dilakukan pada ruangan terbuka agar mendapatkan cahaya matahari yang cukup dan merata. Penanaman tumbuhan di ruang terbuka memiliki beberapa kekurangan diantaranya cuaca yang tidak bersahabat bagi tanaman itu sendiri. Akibat faktor dari cuaca yang tidak bersahabat, sistem vertikultur ini dilengkapi dengan atap yang berfungsi untuk melindungi tanaman vertikultur dari hujan.

Teknik vertikultur dapat digabungkan dengan salah satu metode dari hidroponik yaitu metode Nutrient Film Technique (NFT). Metode pembudidayaan tanaman NFT menggunakan lapisan nutrisi yang dangkal untuk akar tanaman sehingga mendapatkan air, nutrisi, dan oksigen. Penggunaan kata film dari metode NFT menunjukkan nutrisi yang mengalir sangat tipis dengan ketinggian air hanya beberapa milimeter saja (sekitar 3-5 $\mathrm{mm}$ ) dari dasar talang atau pipa Polyvinyl Chloride (PVC), seperti film negative foto [1]. Tanaman akan tumbuh

\footnotetext{
${ }^{1}$ Program Studi Teknik Elektro, Fakultas Teknik, Universitas Tarumanagara

2 Jurusan Teknik Elektro, Universitas Katholik Indonesia Atmajaya
} 
dengan akar yang terendam dalam air nutrisi dan disirkulasikan secara terus menerus dengan pompa selama 24 jam.

Tanaman memiliki ragam jenis buah-buahan dan sayuran. Penanaman tanaman jenis buah-buahan dengan menggunakan metode NFT terdiri dari tomat, strawberry, ketimun, cabai dll, sedangkan tanaman jenis sayuran terdiri dari selada, sawi, bayam, kangkung, pak-choi dll. Jenis tanaman yang digunakan pada rancangan sistem vertikultur metode NFT adalah jenis tanaman sayuran. Tanaman sayuran yang digunakan adalah tanaman selada. Tanaman selada memiliki akar serabut, daunnya berwarna hijau dan batangnya yang keriting yang merupakan jenis selada keriting hijau. Tanaman selada sangat baik di daerah beriklim tropis dan dapat tumbuh pada dataran rendah mau pun dataran tinggi, sehingga tanaman selada dapat digunakan pada pengaplikasian sistem vertikultur metode NFT.

Perancangan sistem vertikultur dengan metode hidroponik diperoleh dari data melalui survei yang dilakukan di Tarumanagara Knowledge Centre (TKC) Universitas Tarumanagara. TKC memiliki dua bentuk vertikultur. Bentuk vertikultur pertama adalah vertikultur rak dinding yang menggunakan metode NFT. Metode NFT pada vertikultur rak dinding diperlukan saluran masuk larutan nutrisi dan saluran pembuangan. Aliran nutrisi yang dipompa mengalir ke atas menuju tiap talang dan aliran nutrisinya akan mengalir ke bawah dengan gaya gravitasi hingga kembali masuk ke dalam tangki air. Vertikultur ini di tempatkan di dalam ruangan tertutup (indoor), sehingga memerlukan cahaya tambahan berupa lampu Light Emitting Diode (LED) sebagai pengganti sinar matahari. Bentuk vertikultur yang kedua adalah vertikultur pipa atau dapat disebut sebagai tower dengan menggunakan metode sistem air mancur, di mana larutan nutrisi dipompa mengalir ke atas melalui pipa kecil di tengah pipa PVC besar ke tempat penampungan air sementara. Tempat penampungan sementara ini terdapat empat buah lubang kecil untuk menjatuhkan nutrisinya ke bawah pada pipa PVC yang besar sehingga menyerupai butiran-butiran air nutrisi yang berjatuhan dan dapat diserap oleh akar tanaman. Vertikultur ini berada di rumah kaca yang menyebabkan tanaman tidak mendapatkan cahaya secara merata.

Survei kedua berada di pameran flora dan fauna lapangan banteng terdapat berbagai macam bentuk vertikultur dengan menggunakan metode hidroponik yang berbeda. Bentuk vertikultur yang terdapat di lapangan banteng adalah vertikultur segitiga dan zig-zag. Bentuk vertikultur pertama adalah vertikultur segitiga menggunakan metode NFT, di mana aliran larutan nutrisi ini dipompa ke bagian talang yang paling atas, lalu aliran tersebut mengalir berputar menuju tangki air dengan saluran pembuangan. Sedangkan bentuk kedua dari vertikultur adalah vertikultur zig-zag menggunakan metode NFT dengan sistem kinerja peraliran nutrisinya sama seperti bentuk vertikultur segitiga. Bentuk dari kedua vertikultur tersebut, di tempatkan di luar ruangan (outdoor) sehingga vertikultur ini dilengkapi dengan penutup atap untuk melindungi tanaman dari turunnya hujan.

Alat yang dirancang adalah model vertikultur yang disusun menjadi tiga tingkatan dan menggunakan pipa PVC berukuran 4 inci sebagai pot tanaman dengan panjang berukuran $30 \mathrm{~cm}$. Selain itu, tiap pipa dapat menanam dua tanaman yang telah diberi penyangga agar tanaman dapat berdiri dengan tegak atau tidak saling berdekatan. Permukaan bawah di dalam pipa dilapisi steroform agar dapat mengukur ketinggian larutan nutrisi. Larutan nutrisi mengalir dari dalam tangki air menuju ketiga pipa pot tanaman, kemudian larutan nutrisi tersebut dikembalikan ke dalam tangki air untuk dialirkan atau digunakan kembali pada ketiga pipa pot tanaman dengan menggunakan pompa air. Aliran nutrisi tersebut menggunakan prinsip hidroponik metode NFT. Masing-masing pot pipa diberi jarak sejauh $20 \mathrm{~cm}$. Pemberian jarak dilakukan untuk mengantisipasi tanaman tumbuh tinggi ke atas. Pembuatan sistem vertikultur dilengkapi dengan atap yang berfungsi melindungi tanaman dari turunnya hujan. Keseluruhan sistem vertikultur dapat direalisasikan pada ruangan terbuka, seperti perkarangan rumah atau halaman rumah.

Perancangan ini bertujuan untuk mengotomatisasi sistem vertikultur metode NFT dalam hal penerimaan cahaya matahari dan pengendalian pengairan larutan nutrisi. Perancangan ini merancang modul catu daya, modul driver LDR, modul motor driver, modul pendeteksi batas gerak motor dan modul pendeteksi ketinggian larutan nutrisi. Sedangkan untuk modul yang tidak dirancang adalah modul pemroses. Spesifikasi pada rancangan ini adalah menggunakan catu daya sebsar $5 \mathrm{~V}$ dan $12 \mathrm{~V}$, menggunakan mikrokontroler, menggunkan enam buah sensor Light Dependent Resistor (LDR) dengan desain membentuk sudut $45^{\circ}$ sampai $135^{\circ}$, menggunakan motor Direct Current (DC) power window dengan rantai gear motor, pompa air dengan debit 2400 liter per jam dan terdapat alarm sebagai indikator pada pencapaian batas minimum larutan nutrisi.

\section{Deskripsi Konsep}

Sistem vertikultur mencakup modul pengendali pendeteksi cahaya dan modul pendeteksi batas gerak aktuator sebagai input, modul pemroses serta modul pengendali aktuator sebagai output dari sistem, dapat dilihat pada Gambar 1. Modul pendeteksi cahaya terdiri dari enam buah modul yang dipasang membentuk sudut $45^{\circ}$ sampai $135^{\circ}$. Modul ini dapat bekerja berdasarkan pembacaan kondisi cahaya terang dan gelap. Modul tersebut memberikan informasi ke modul pemroses untuk menggerakkan modul aktuator vertikultur dan mengarahkan vertikultur ke arah cahaya matahari. Pada modul aktuator vertikultur berfungsi untuk menggerakkan vertikultur yang dikendalikan oleh modul pengendali aktuator vertikultur. Modul pengendali aktuator vertikultur akan 
menerima informasi dari modul pemroses sehingga modul aktuator dapat bergerak mengikuti cahaya matahari yang terfokus dengan mengatur kecepatan gerak aktuator dari modul pendeteksi cahaya. Selain itu, terdapat modul

pendeteksi batas aktuator sebagai pembatas minimum dan maksimun gerak modul aktuator. Modul pendeteksi batas aktuator memberikan informasi berupa logika high dan low kepada modul pemroses.

Pembatasan penggunaan larutan nutrisi dilakukan pada modul pendeteksi batas ketinggian larutan nutrisi dengan batas ketinggian tertentu. Pengaturan modul pendeteksi batas ketinggian larutan nutrisi menggunakan sistem on/off yang terhubung dengan modul catu daya. Modul catu daya memberikan tegangan ke modul pendeteksi batas ketinggian larutan nutrisi untuk menghidupkan indikator. Informasi yang diterima merupakan tanda peringatan bagi pengguna untuk melakukan pengisian ulang larutan nutrisi secara manual. Modul indikator akan hidup apabila modul pendeteksi batas ketinggian larutan nutrisi dalam keadaan on dan modul ini akan berhenti apabila modul pendeteksi batas ketinggian larutan nutrisi dalam keadaan off atau jika sudah melakukan pengisian ulang. Diagram blok pendeteksi ketinggian larutan nutrisi dapat dilihat pada Gambar 2.

\section{Diagram Blok}

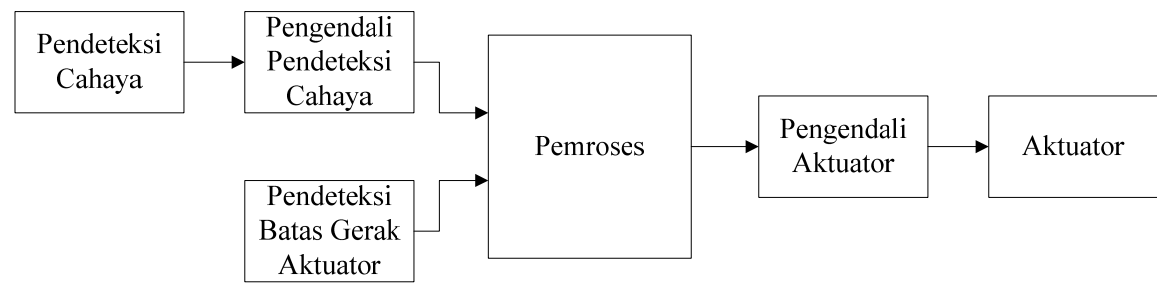

- Gambar 1. Diagram Blok Pergerakan Sistem Vertikultur

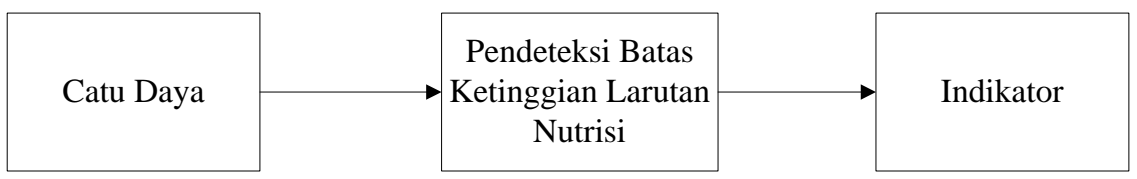

- Gambar 2. Diagram Blok Pendeteksi Ketinggian Larutan Nutrisi

\section{Metode Nutrient Film Technique (NFT)}

Metode NFT adalah salah satu pembudidayaan tanaman hidroponik yang paling popular dalam bidang pekebunan komersial. Pembudidayaan tanaman metode NFT membutuhkan larutan nutrisi yang mengalir secara terus-menerus selama 24 jam. Tanaman membutuhkan lapisan nutrisi yang mengalir sangat tipis setinggi 3-5 mm dari dasar permukaan saluran. Tinggi nutrisi yang diperlukan seperti tampak film negatif foto. Pembuatan aliran larutan nutrisi yang dilewatkan dalam saluran berupa talang air atau pipa diletakkan dengan kemiringan tertentu. Kemiringan talang yang disarankan sekitar $1,5-5^{\circ}$ [2]. Kemiringan tersebut membuat larutan nutrisi mengalir ke posisi yang lebih rendah. Cara kerja metode NFT dapat dilihat pada Gambar 3.

Lubang tanam dibuat dengan menyesuaikan jenis tanaman yang ditanam sebagai tempat bertumbuhnya tanaman. Jarak antar lubang dibedakan menjadi dua jenis pertumbuhan tanaman yaitu tanaman yang tumbuh ke atas seperti kangkung memerlukan jarak sekitar $5 \mathrm{~cm}$ dan tanaman tumbuh yang merekah seperti selada memerlukan jarak sekitar $15 \mathrm{~cm}$. Talang atau pipa PVC dapat disusun sejajar membentuk meja yang rata, bertingkat kemudian di tempatkan merapat di satu sisi dinding, bertingkat ke atas dalam rak, atau bertingkat dengan rangka segitiga sama kaki. Berbagai bentuk pilihan dapat disesuaikan denagan luasan lahan.

Teknik NFT dapat dilakukan di lahan terbuka dan greenhouse atau nethouse. Penanaman hidroponik menggunakan metode NFT di lahan terbuka membutuhkan investasi yang lebih rendah dibandingkan menggunakan greenhouse. Hal ini menyebabkan pekebun lebih berhati-hati akan serangan hama dan penyakit yang muncul serta intensitas hujan yang berlebih pun mengubah kandungan nutrisi. Pembangunan rumah tanam menggunakan greenhouse membutuhkan investasi yang tinggi, karena terdapat penggunaan atap untuk tanaman lebih terlindungi dari serangan hama, penyakit dan hujan. 


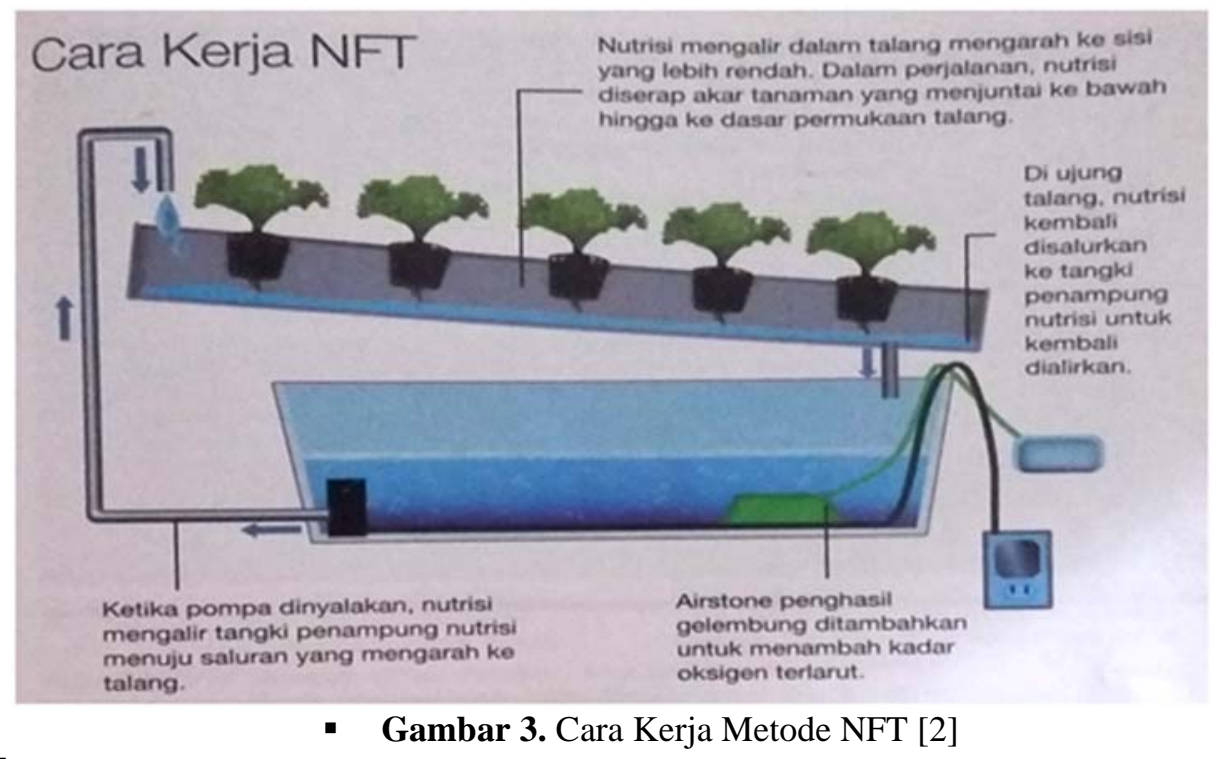

\section{Mikrokontroler}

Mikrokontroler adalah suatu sistem komputer yang berfungsi sebagai pusat untuk mengolah data dan memproses seluruh perintah dari sebuah sistem. Fungsi utama mikrokontroler adalah untuk mengontrol operasi sebuah sistem yang menggunakan program tetap dan disimpan dalam Read Only Memory (ROM), karena data pada ROM bersifat permanen [2]. Pada umumnya, desain pada sistem mikrokontroler memiliki CPU dan dilengkapi dengan fitur-fitur lainnya yaitu RAM, ROM, Port I/O, timer dan serial I/O.

Arsitektur pada mikrokontroler berdasarkan desain CPU dan set instruksi yaitu Complex Instruction Set Computers (CISC) dan Reduced Instruction Set Computers (RISC). CISC adalah arsitektur komputer dengan kumpulan instruksi yang kompleks atau rumit. RISC adalah arsitektur komputer dengan kumpulan instruksi yang sederhana. Karakteristik instruksi yang dieksekusi pada arsitektur CISC membutuhkan waktu pemrosesan data cukup lama. Namun berbeda halnya dengan arsitektur RISC, waktu yang dibutuhkan untuk pemroses data lebih cepat karena instruksi yang digunakan lebih sederhana. Contoh arsitektur komputer berbasis CISC dari mikrokontroler adalah CPU AMD dan Intelx86 sedangkan contoh dari mikrokontroler arsitektur komputer berbasis RISC adalah ARM dan AVR.

Sistem vertikultur metode NFT menggunakan mikrokontroler AVR dengan arsitektur komputer berupa RISC. Kelompok AVR dibagi menjadi empat grup yaitu ATMega, ATTiny, AVR klasik dengan tiga tipe series AT90Sxx dan Special Purpose AVR yang terdiri dari tiga tipe series AT90xx dan ATMega169. Fitur-fitur yang dimiliki pada mikrokontroler AVR adalah EEPROM, PORT I/O, Analog to Digital Converter (ADC), Pulse Width Modulation (PWM), timer,counter dan berbagai macam komunikasi serial. Pemrogramam yang digunakan pada mikrokontroler AVR dibagi menjadi dua bahasa yaitu bahasa tingkat rendah (low level language) seperti bahasa mesin atau (machine assembly) atau bahasa tingkat tinggi (high level language) seperti $\mathrm{C} / \mathrm{C}++$. Sistem vertikultur menggunakan mikrokontroler AVR tipe ATMega dengan bahasa pemrograman C.

\section{Light Dependent Resistor (LDR)}

LDR merupakan komponen elektronika jenis resistor yang dipengaruhi oleh rangsangan terhadap cahaya. LDR adalah sebuah tipe sensor resistor dengan nilai resistansi yang diterima tergantung pada intensitas cahaya, sehingga mengalami perubahan pada nilai resistansi. Perubahan resistansi didapat dari banyaknya cahaya yang diperoleh dari LDR. Besar nilai intensitas cahaya yang diterima mempengaruhi nilai resistansi LDR, dengan demikian dapat dideteksi kondisi cahaya yang semakin gelap dan terang. Hal tersebut berkaitan dengan fungsi LDR yaitu dapat menerima sejumlah intensitas cahaya untuk menghantarkan arus listrik dalam kondisi terang dan menghambat arus listrik dalam kondisi gelap.

\section{Operational Amplifier (OP-Amp)}

Operational amplifier (Op-Amp) merupakan suatu rangkaian amplifier yang dikemas dalam bentuk Integrated Circuit (IC). Konfigurasi Op-Amp memiliki dua konfigurasi dasar yaitu sebagai inverting amplifier dan non-amplifier. Dari kedua konfigurasi dasar tersebut dapat dikembangkan menjadi rangkaian filter, osilator, buffer, integrator, penjumlahan dan komparator.

Komparator merupakan salah satu aplikasi dari sebuah rangkaian Op-Amp. Penggunaan Op-Amp sebagai komparator berfungsi untuk merubah sinyal analog menjadi sinyal digital atau untuk merepresentasikan nilai kondisi berupa high dan low atau dapat +VCC dan -VCC. Simbol komparator pada Op-Amp dapat dilihat pada Gambar 4 yang menunjukkan kaki positif merupakan tegangan input sedangkan kaki negatif merupakan tegangan referensi dengan satu terminal output. 


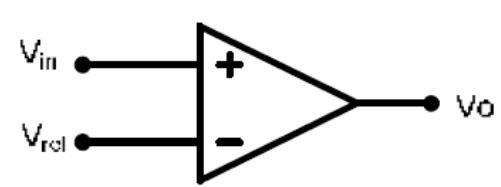

- Gambar 4. Simbol Komparator Op-Amp [3]

Hasil output yang dihasilkan sangat tergantung pada perbandingan kedua input dari Op-Amp yang digunakan, berikut beberapa sifat yang dimiliki oleh komparator:

1. Pada kaki non-inverting (+), jika Vin $<$ Vref maka Vo $=$ low dan Vin $>$ Vref maka Vo $=$ high

2. Begitu pun sebaliknya, pada kaki inverting (-), jika Vin $<$ Vref maka Vo $=$ high dan Vin $>$ Vref maka $V_{o}=$ low.

\section{Motor DC}

Motor DC adalah suatu mesin elektrik magnetik yang berfungsi untuk mengubah energi listrik menjadi energi mekanik. Motor DC memiliki dua bagian utama yaitu stator dan rotor. Stator adalah bagian yang tidak berputar atau tetap disebut sebagai kumparan medan pada motor. Rotor adalah bagian yang dapat berputar yang disebut sebagai kumparan jangkar. Motor DC dapat berputar ketika diberi suplai tegangan dari catu daya. Arah putaran motor DC tergantung dari pemasangan polaritas kutub dari catu daya dengan motor agar dapat berputar searah jarum jam atau berlawanan arah jarum jam.

\section{Motor Driver}

Motor driver berfungsi untuk mengatur arah dan kecepatan putaran motor serta mensuplai arus yang cukup pada motor DC. Ditinjau dari penggunaannnya, motor driver sebagai modul perantara dari mikrokontroler dengan motor DC. Motor driver diperlukan karena ketersediaan arus keluaran dari mikrokontroler tidak mencukupi untuk menghidupkan motor DC dengan arus yang dimiliki oleh motor DC. Motor driver dapat mengatur arah putaran motor DC dari searah jarum jam menjadi berlawanan arah jarum jam, begitu pun dari arah sebaliknya. Selain itu, motor driver diatur kecepatan putaran motor DC dengan cara mengatur PWM untuk mengaktifkan dan menonaktifkan gerak motor DC.

\section{Light Emitting Diode (LED)}

Light emitting diode (LED) atau dioda pemancar cahaya adalah suatu perangkat elektronik semikonduktor yang mengubah energi listrik menjadi energi cahaya. Berbagai banyak macam warna LED dipasaran yaitu ada warna putih, merah, hijau, biru dan kuning. Warna yang dihasilkan pada LED tergantung dari bahan semikonduktor dan pada wavelength (panjang gelombang).

\section{Saklar}

Saklar merupakan alat penyambung dan pemutus aliran arus listrik yang masuk ke dalam suatu rangkaian. Pengoperasian saklar dapat dilakukan dengan normally open (NO) dan normally close (NC). Prinsip kerja saklar dalam pengoperasian $\mathrm{NO}$ adalah kondisi awal posisi saklar dalam keadaaan open, kemudian ketika saklar ditekan maka akan berubah posisi saklar dalam keadaan close. Sedangkan, prinsip kerja saklar dalam pengoperasian NC adalah kondisi awal saklar berada dalam keadaan close dan ketika ditekan akan berubah menjadi keadaan open.

\section{Buzzer}

Buzzer adalah perangkat elektronik yang digunakan untuk memberi tanda peringatan berupa suara atau dengan kata lain dapat digunakan sebagai alarm. Buzzer menghasilkan suara atau bunyi dengan satu nada yang berfrekuensi sangat tinggi dan bersifat kontinu. Penggunaan buzzer cocok untuk aplikasi pada bel pintu.

\section{Modul Catu Daya}

Modul catu daya pada perancangan ini adalah modul yang menghasilkan keluaran tegangan DC [4]. Tegangan DC yang digunakan berupa tegangan sebesar $12 \mathrm{~V}$ dan $5 \mathrm{~V}$ dengan arus $2 \mathrm{~A}$. Tegangan DC tersebut didapatkan dari tegangan PLN berupa tegangan Alternative Current (AC) yang dikonversi ke tegangan DC. Sinyal tegangan keluaran dari transformator masih berupa tegangan AC lalu oleh diode bridge tersebut diubah menjadi tegangan DC. Sinyal pada tegangan DC secara terus-menerus mengisi muatan kapasitor hingga mencapai tegangan puncak. Tegangan pada kapasitor jatuh dari level puncak, kemudian tegangan dikembalikan ke level puncak sinyal berikutnya sehingga menghasilkan gelombang riak (ripple). Gelombang tersebut distabilkan dengan menggunakan IC regulator. IC regulator yang digunakan adalah LM7805 untuk menstabilkan sinyal tegangan keluaran DC menjadi 5 V dan LM7812 untuk menstabilkan sinyal tegangan DC menjadi $12 \mathrm{~V}$. Tegangan $5 \mathrm{~V}$ dan $12 \mathrm{~V}$ dirangkai 
secara paralel agar modul-modul yang dirancang mendapat tegangan sesuai kebutuhan. Kebutuhan catu daya $5 \mathrm{~V}$ diperlukan untuk mengaktifkan modul mikrokontroler, modul driver LDR, modul pendeteksi batas gerak motor dan modul pendeteksi ketinggian larutan nutrisi, sedangkan catu daya $12 \mathrm{~V}$ hanya mengaktifkan motor DC. Catu daya $5 \mathrm{~V}$ dan $12 \mathrm{~V}$ diberi LED dengan warna yang berbeda. Warna LED yang digunakan pada catu daya $5 \mathrm{~V}$ adalah LED warna merah sedangkan pada catu daya $12 \mathrm{~V}$ adalah LED warna putih. LED tersebut berfungsi sebagai indikator untuk membedakan catu daya $5 \mathrm{~V}$ dengan catu daya $12 \mathrm{~V}$. Selain itu, modul catu daya menggunakan heatsink sebagai pendingin untuk regulator LM7805 dan LM7812.

\section{Modul Driver LDR}

Konstruksi pendeteksi cahaya berupa LDR seperti pada Gambar 5, didesain dengan membentuk format sudut $45^{\circ}$ sampai $135^{\circ}$. LDR yang digunakan terdiri dari enam buah sensor dan dapat mengikuti arah pergerakan matahari (dari timur ke barat). Tiap LDR diberi sekat dan dilapisi karton hitam untuk mempermudahkan cahaya yang masuk hanya terfokus pada salah satu sensor saja. Perancangan modul driver LDR dirancang berdasarkan pengukuran tegangan output dari tegangan referensi untuk menentukan atau membedakan kondisi cahaya gelap dan terang, seperti pada Tabel 1. Perbedaan nilai tegangan output dari kedua kondisi tersebut didapat nilai tegangan referensi. Tegangann referensi digunakan sebagai nilai pembanding yang mengindikasikan kondisi dari cahaya matahari.

Skematik modul driver LDR terdiri dari voltage divider dan komparator Op-Amp, seperti pada Gambar 6. Konsep voltage divider dapat digunakan untuk menghitung tegangan dari LDR pada kaki positif atau disebut sebagai tegangan input (Vin). Vin dibandingkan dengan tegangan dari komparator Op-Amp pada kaki negatif atau disebut sebagai tegangan referensi (Vref). Jika Vin lebih besar dari Vref maka tegangan output (Vout) dari modul driver LDR menghasilkan sinyal high. Sinyal high yang dihasilkan akan sama dengan V+ (VCC). Sebaliknya, jika Vin lebih besar dari Vref maka Vout dari modul driver LDR menghasilkan sinyal low. Sinyal low yang dihasilkan akan sama dengan V- (ground).

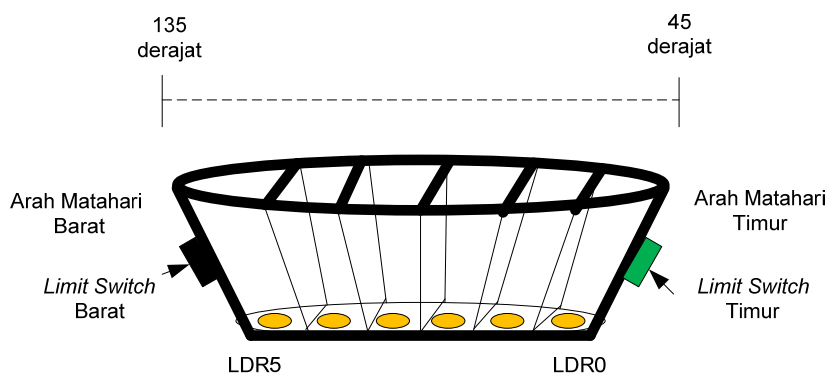

- Gambar 5. Konstruksi LDR
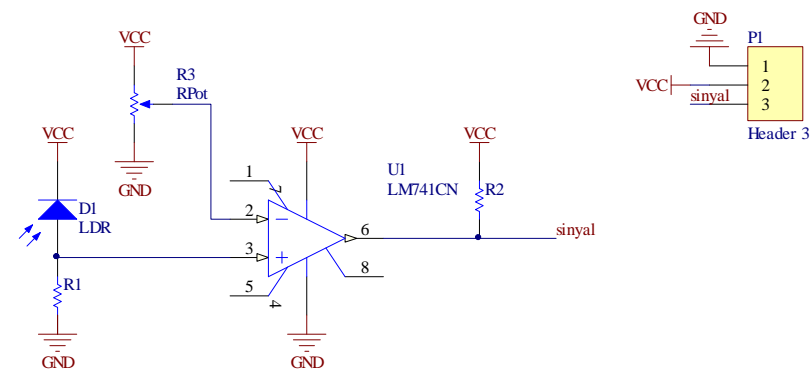

- Gambar 6. Skematik Modul Driver LDR

- Tabel 1. Perkiraan Pembacaan LDR

\begin{tabular}{cc}
\hline Kondisi Cahaya & Tegangan (Volt) \\
\hline Gelap & Tegangan output $<$ tegangan referensi \\
Terang & Tegangan output $>$ tegangan referensi
\end{tabular}

\section{Modul Motor Driver}

Konstruksi pada motor DC seperti pada Gambar 7, dibentuk menyerupai rantai sepeda yang terdiri dari gear besar, gear kecil dan rantai motor. Motor DC dipasangkan gear kecil untuk mengatur besar atau kecilnya laju putaran motor dan terdapat juga gear besar yang terpasang langsung pada sistem vertikultur. Gear-gear yang telah dipasang dapat dihubungkan menggunakan rantai motor agar gear besar dapat menyesuaikan arah dan kecepatan gerak dari gear kecil pada motor DC yang dikendalikan oleh mikrokontroler. Kecepatan gerak motor DC diatur berdasarkan posisi LDR untuk dapat mengetahui keberadaan sudut yang dituju, seperti pada Tabel 2. 
Referensi sudut dapat dilihat pada Gambar 5, di mana posisi LDR0 sampai LDR5 merupakan arah pergerakkan dari matahari.

Skematik modul motor driver dapat dilihat pada Gambar 8. Realisasi modul motor driver dilakukan untuk mengatur arah dan kecepatan gerakkan pada vertikultur agar dapat berputar searah dan berlawanan arah jarum jam berdasarkan PWM dari mikrokontroler. Output dari mikrokontroler terhubung dengan input 1,4 dan input 2,3 pada IC LM289 untuk mengatur arah gerak motor. LM289 memiliki pin enable a dan b untuk mengaktifkan motor dan mengatur kecepatannya. Pin input dan enable diatur oleh sinyal dari mikrokontroler untuk mengatur arah gerak putaran berserta PWM pada motor agar gerakkan motor terkendali. Rangkaian motor driver membutuhkan tegangan masukan sebesar $12 \mathrm{~V}$ untuk motor DC dan $5 \mathrm{~V}$ untuk input PWM dari mikrokontroler. Mikrokontroler menerima setiap input dari LDR sehingga motor DC dapat diatur PWM berdasarkan pada arah pergerakkan matahari (dari timur ke barat) dengan panjang vertikultur. Motor dapat bergerak dan berhenti pada posisi sudut yang telah ditentukan.

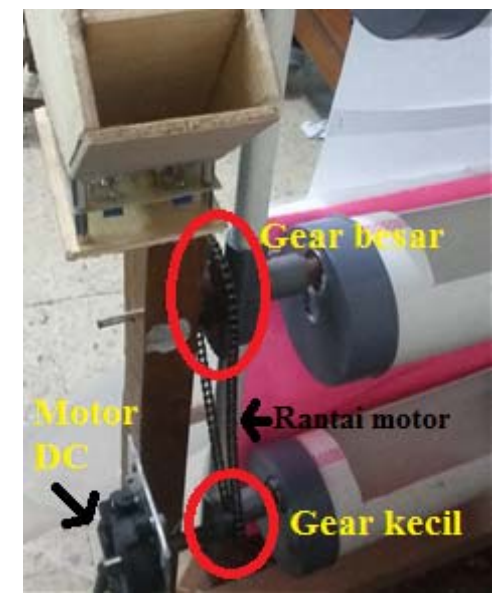

- Gambar 7. Konstruksi Motor DC

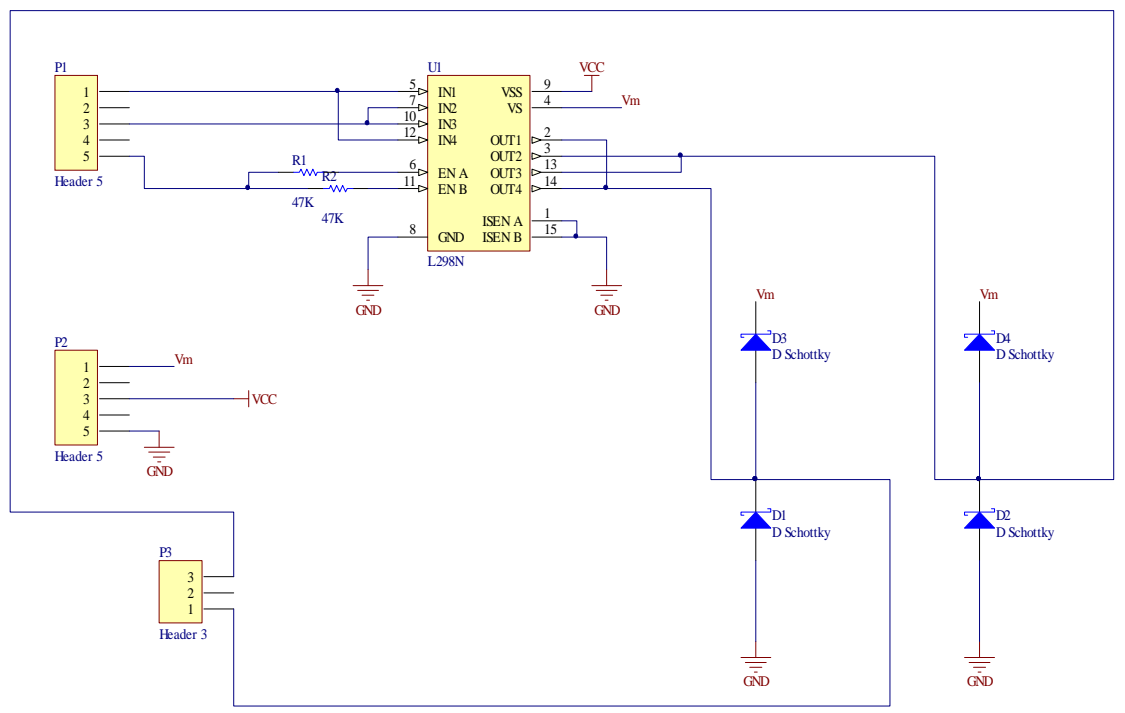

- Gambar 8. Skematik Modul Motor Driver

- Tabel 2. Menentukan Sudut Tujuan Vertikultur dari Posisi LDR

\begin{tabular}{cc}
\hline Posisi Vertikultur dan Pembacaan LDR & Sudut Tujuan $\left(^{\circ}\right)$ \\
\hline Vertikultur & 90 \\
LDR0 & 105 \\
LDR1 & 120 \\
LDR2 & 135 \\
LDR3 & 45 \\
LDR4 & 60 \\
LDR5 & 75 \\
\hline
\end{tabular}




\section{Modul Pendeteksi Ketinggian Larutan Nutrisi}

Vertikultur yang dirancang menggunakan satu buah limit switch dengan seutas tali yang diberi beban sebagai pendeteksi batas minimum pada persediaan larutan nutrisi. Beban yang digunakan adalah balok kayu kecil karena tidak terlalu berat dan dapat terapung di atas air. Beban pada limit switch bermula dari keadaan off dan dapat bekerja apabila larutan nutrisi di dalam tangki air telah melampaui batas minimum, maka balok kayu kecil menekan limit switch sehingga keadaan menjadi on. Selain itu, modul ini dilengkapi dengan indikator berupa LED dan buzzer yang berfungsi untuk memberi informasi bahwa larutan nutrisi di dalam tangki air sudah mencapai batas pengisian larutan nutrisi berikutnya. LED dan buzzer menyala ketika limit switch dalam keadaan on atau dapat dikatakan kerja dari rangkaian ini adalah normally open. Rangkaian yang sebelumnya telah dirancang menjadi normally open dapat terhubung langsung dengan power supply. Skematik modul pendeteksi ketinggian larutan nutrisi dapat dilihat pada Gambar 9.

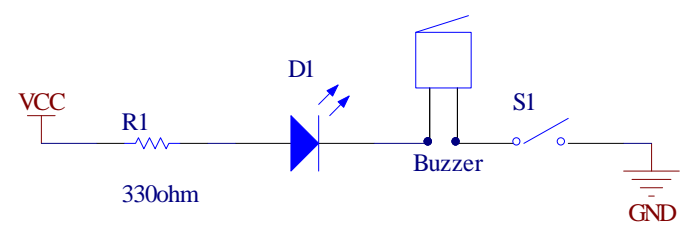

- Gambar 9. Skematik Modul Pendeteksi Ketinggian Larutan Nutrisi

\section{Modul Pendeteksi Batas Gerak Motor}

Realisasi modul pendeteksi batas gerak motor dilakukan dengan menggunakan limit switch. Penggunaan limit switch pada modul ini, membutuhkan dua buah limit switch sebagai batas minimum dan maksimum gerak pada motor. Letak kedua limit switch ini dapat dilihat pada Gambar 5. Limit switch dirancang menjadi rangkaian pull up, sehingga dengan mudah diolah pada mikrokontroler sebagai on/off secara otomatis menjadi normally open. Modul ini bekerja ketika motor bergerak menekan limit switch (mengenai batas minimum atau batas maksimum) agar motor dapat bergerak dengan otomatis. Skematik modul pendeteksi batas gerak motor dapat dilihat pada Gambar 10.

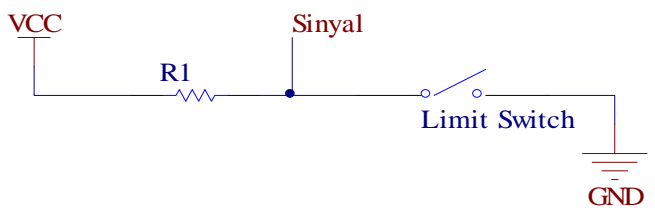

- Gambar 10. Skematik Modul Pendeteksi Batas Gerak Motor

\section{HASIL PENGUJIAN DAN ANALISIS}

Pengujian modul driver LDR dilakukan dengan menggunakan multimeter digital untuk mengukur nilai referensi pada Op-Amp dan voltage divider dari LDR. Pengujian pengukuran voltage divider dari LDR dilakukan dengan memutar trimpot pada dua kondisi yaitu pada saat terang dan gelap. Pengujian ini dilakukan pada kondisi terang dan gelap dengan menghubungkan kabel positif multimeter ke kaki 3 IC LM741 dan kabel negatif pada multimeter dihubungkan ke ground. Selanjutnya, pengujian pengukuran tegangan referensi dilakukan dengan memutarkan trimpot dengan kabel positif multimeter dihubungkan ke kaki 2 IC LM741 dan kabel negatif dihubungkan ke ground. Pengukuran tegangan referensi didapat dari hasil pengujian voltage divider LDR dalam keadaan terang dan gelap yang dibagi dua, seperti pada Tabel 3. Berdasarkan hasil pengujian modul driver LDR dapat beroperasi dengan baik, sehingga modul ini dapat mengindikasikan kondisi dari cahaya matahari.

- Tabel 3. Hasil Pengujian Modul Driver LDR

\begin{tabular}{cccc}
\hline LDR & Tegangan Referensi (Volt) & $\begin{array}{c}\text { Tegangan dalam } \\
\text { Kondisi Gelap (Volt) }\end{array}$ & $\begin{array}{c}\text { Tegangan dalam } \\
\text { Kondisi Terang (Volt) }\end{array}$ \\
\hline LDR0 & 3,174 & 1,924 & 5,01 \\
LDR1 & 3,183 & 1,900 & 5,01 \\
LDR2 & 3,188 & 1,901 & 5,01 \\
LDR3 & 3,192 & 1,911 & 5,01 \\
LDR4 & 3,172 & 1,909 & 5,01 \\
LDR5 & 3,165 & 1,913 & 5,01 \\
\hline
\end{tabular}


Pengujian modul motor driver dilakukan dengan menyambungkan VCC dan ground pada input 1 dan input 2. Enable pada modul driver motor terhubung VCC yang bertujuan untuk mengaktifkan motor. Hasil pengujian menunjukkan logika " 00 " dan " 11 " motor tidak bergerak atau dalam posisi diam dan motor berhenti bergerak, jika diberi logika "01” maka motor bergerak berlawanan arah jarum jam sedangkan logika "10” motor

dapat bergerak searah jarum jam. Berdasarkan hasil pengujian seperti pada Tabel 4, motor dapat bergerak searah jarum jam dan berlawanan arah jarum jam. Pengujian PWM motor dilakukan dengan membuat program sederhana seperti pada Gambar 11, motor bergerak berlawanan arah jarum jam dengan setengah kecepatan maksimal dari motor. Berdasarkan hasil pengujian program sederhana, motor dapat diatur arah dan PWM dari mikrokontroler.

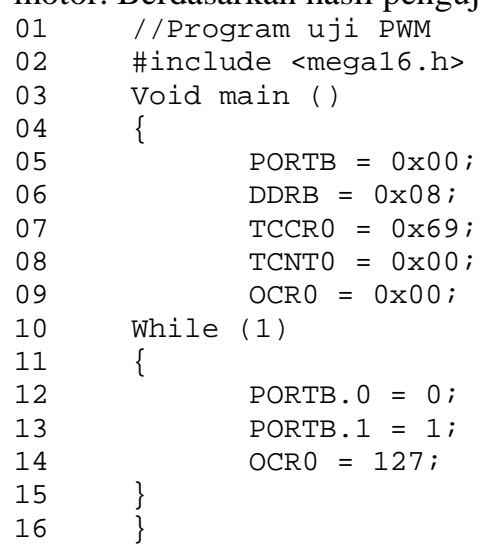

- Gambar 11. Pengujian PWM

- Tabel 4. Hasil Pengujian Modul Motor Driver

\begin{tabular}{cccc}
\hline Input 1 & Input 2 & Enable & Arah \\
\hline 0 & 0 & High & Diam \\
0 & 1 & High & CCW \\
1 & 0 & High & CW \\
1 & 1 & High & Diam \\
\hline
\end{tabular}

Pengujian mikrokontroler dilakukan dengan membuat contoh program sederhana untuk menghidupkan atau mematikan LED dengan delay 1 detik, seperti pada Gambar 12. Pada nomor 11 dan 12 berfungsi untuk mengeluarkan tegangan selama 1000 ms atau sama dengan 1 detik. Sedangkan, pada nomor 13 dan 14 berfungsi untuk menghentikan keluaran tegangan atau tidak ada tegangan selama 1000 ms atau sama dengan 1 detik. Hasil pengujian modul mikrokontroler adalah barisan LED menyala kedap-kedip secara bersamaan. Hal ini berarti, semua PORT yang digunakan menghasilkan logika "0" dan "1" secara bergantian. Jumlah LED yang digunakan sebanyak 8 buah yang merepersentasikan penggunaan 8 bit. Program sederhana ini menunjukkan mikrokontroler dapat berjalan dengan baik sehingga mikrokontroler dapat digunakan sebagai pengolah data dan pengendali jalannya seluruh sistem.

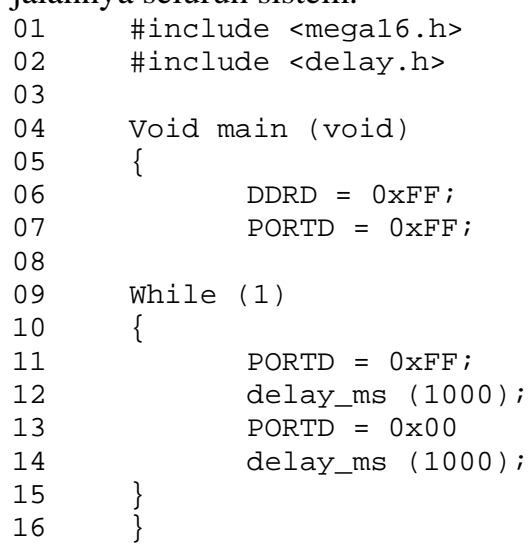

- Gambar 12. Pengujian Mikrokontroler

Rangkaian modul pendeteksi batas gerak motor dilakukan pengujian dengan mengukur tegangan dalam keadaan on/off. Pengukuran dilakukan dengan menggunakan multimeter digital dalam kondisi ditekan dan tidak 
ditekan pada limit switch. Hasil pengujian modul pendeteksi batas gerak motor, kedua limit switch yang berada pada arah timur dan barat akan aktif atau berlogika "1" apabila diberi tegangan $5 \mathrm{~V}$ dari modul catu daya sehingga modul dapat digunakan sebagai pembatas gerak pada motor dan modul ini tidak aktif atau berlogika "0" apabila tidak diberi tegangan. Berdasarkan hasil pengujian modul pendeteksi batas gerak motor dapat berfungsi ketika ditekan atau bekerja secara normally open. Hasil pengujian modul pendeteksi batas gerak motor pada limit switch yang berada di arah timur dan barat dapat dilihat pada Tabel 5.

- Tabel 5. Hasil Pengujian Modul Pendeteksi Batas Gerak Motor

\begin{tabular}{ccc}
\hline Posisi Limit switch & Kondisi Limit Switch & Tegangan Output pada Limit Switch (Volt) \\
\hline \multirow{2}{*}{ Timur } & 0 & 0 \\
& 1 & 5,01 \\
\hline \multirow{2}{*}{ Barat } & 0 & 0 \\
& 1 & 5,01 \\
\hline
\end{tabular}

Pengujian modul pendeteksi ketinggian larutan nutrisi diberi tegangan sebesar $5 \mathrm{~V}$ dari rancangan modul catu daya. Pengujian dilakukan dengan menghubungkan langsung modul pendeteksi ketinggian larutan nutrisi dengan modul catu daya tanpa harus terprogram dari mikrokontroler. Hasil pengujian menunjukkan limit switch bekerja ketika posisi dalam keadaan ditekan atau berlogika "1" yang dapat menghidupkan LED dan buzzer. Sedangkan ketika posisi dalam keadaan tidak ditekan atau berlogika "0" maka LED dan buzzer tidak dapat menyala. Modul pendeteksi ketinggian larutan nutrisi dapat berjalan sesuai fungsinya untuk mendeteksi level minimum larutan nutrisi di dalam tangki. Hasil pengujian modul pendeteksi ketinggian larutan nutrisi dapat dilihat pada Tabel 6. Modul ini dirancang agar menghindari kerusakan pada pompa air apabila ketersediaan larutan nutrisi dalam tangki tidak mencukupi.

- Tabel 6. Hasil Pengujian Modul Pendeteksi Ketinggian Larutan Nutrisi

\begin{tabular}{ccccc}
\hline Tegangan & Kondisi Limit Swicth & LED & Buzzer & Keterangan \\
\hline \multirow{2}{*}{$5 \mathrm{~V}$} & 0 & Tidak Menyala & Tidak Berbunyi & Mati \\
& 1 & Menyala & Berbunyi & Hidup \\
\hline
\end{tabular}

Pengujian tinggi larutan nutrisi pada pot tanaman merupakan pengujian yang dilakukan untuk metode NFT, karena tinggi lapisan larutan nutrisi yang dianjurkan sekitar \pm 3-5 $\mathrm{mm}$. Pengujian dilakukan dengan menggunakan alat ukur mistar untuk mengukur tinggi larutan nutrisi yang dialiri oleh pompa ke pot tanaman. Pengukuran ketinggian larutan nutrisi dilakukan dengan meletakkan mistar memanjang ke atas di dalam pipa yang telah dialiri larutan nutrisi. Pipa tersebut terdapat sterofoam sebagai alas bidang lurus untuk mempermudah melakukan pengukur tinggi larutan nutrisi di dalam pipa. Berdasarkan hasil pengujian seperti pada Tabel 7, masing-masing pot tanaman telah memenuhi syarat dari ketentuan larutan nutrisi yang digunakan untuk metode NFT.

- Tabel 7. Hasil Pengujian Tinggi Larutan Nutrisi pada Pot Tanaman

\begin{tabular}{cc}
\hline Posisi Pot Tanaman & Ketinggian Larutan Nutrisi (mm) \\
\hline Pot tanaman atas & 3 \\
Pot tanaman tengah & 3 \\
Pot tanaman bawah & 4 \\
\hline
\end{tabular}

Pengujian tanaman selada menggunakan metode NFT dilakukan untuk mengecek pertumbuhan tanaman selada dari pengukuran tinggi tanaman, lebar daun dan warna daun. Pengujian dilakukan selama dua hari dengan cahaya matahari. Pengujian ini menggunakan tiga sampel benih tanaman selada yang berusia dua minggu. Hasil pengujian menunjukkan bahwa pertumbuhan tanaman selada tumbuh minimal $2 \mathrm{~mm}$ dalam satu hari. Berdasarkan hasil pengujian pada Tabel 8, tanaman selada dapat tumbuh lebih cepat dengan menggunakan metode NFT dan cahaya matahari.

- Tabel 8. Hasil Pengujian Pertumbuhan Tanaman Selada

\begin{tabular}{llccc}
\hline \multicolumn{1}{c}{ Percobaan } & Pengujian & Selada 1 & Selada 2 & Selada 3 \\
\hline \multirow{4}{*}{ Tinggi tanaman (mm) } & Referensi & 8.6 & 8.9 & 9.2 \\
& Hari pertama & 8.9 & 9.3 & 9.5 \\
& Hari kedua & 9.2 & 9.5 & 9.7 \\
\hline Lebar daun (mm) & Referensi & 1.2 & 1.4 & 1.5
\end{tabular}


Perancangan Sistem Vertikultur Metode Nutrient Film Technique dengan Penyesuaian Arah Gerak Cahaya Matahari Berbasis Mikrokontroler

\begin{tabular}{llccc} 
& Hari pertama & 1.4 & 1.6 & 1.4 \\
& Hari kedua & 1.7 & 1.8 & 1.7 \\
\hline \multirow{3}{*}{ Warna daun } & Referensi & Hijau & Hijau & Hijau \\
& Hari pertama & Hijau & Hijau & Hijau \\
& Hari kedua & Hijau & Hijau & Hijau \\
\hline
\end{tabular}

Pengujian modul catu daya dilakukan dengan cara diuji keluaran tegangan tanpa beban dan keseluruhan beban. Pengujian pertama dilakukan dengan menghubungkan modul catu daya tanpa beban. Pengujian dapat dilakukan dengan menggunakan alat ukur berupa multimeter digital. Multimeter digital digunakan sebagai voltmeter yang berfungsi untuk mengukur tegangan. Pengujian dilakukan dengan multimeter yang dihubungkan paralel dengan modul catu daya. Hasil dari pengujian modul catu daya tanpa beban memperoleh nilai keluaran tegangan sesuai dengan besaran tegangan input dari penggunaan IC regulator yang digunakan, seperti pada Tabel 9. Berdasarkan hasil pengujian modul catu daya tanpa beban dapat berfungsi dan beroperasi dengan baik.

- Tabel 9. Hasil Pengujian Modul Catu Daya Tanpa Beban

\begin{tabular}{cc}
\hline Tegangan Input (Volt) & Tegangan Output (Volt) \\
\hline $5 \mathrm{~V}$ & $5.01 \mathrm{~V}$ \\
$12 \mathrm{~V}$ & $11.99 \mathrm{~V}$ \\
\hline
\end{tabular}

Pengujian kedua dilakukan dengan menghubungkan modul catu daya pada beban keseluruhan. Pengujian tersebut untuk mengukur tegangan output dari beban keseluruhan. Pengujian dilakukan dengan menggunakan multimeter yang dihubungkan secara paralel antara modul catu daya dengan beban. Dari hasil pengujian, nilai tegangan keluaran dari input $5 \mathrm{~V}$ atau $12 \mathrm{~V}$ mengalami penurunan. Hal ini menunjukkan bahwa tiap modul mendapat suplai tegangan yang dibutuhkan. Berdasarkan hasil pengujian modul catu daya pada beban keseluruhan seperti pada Tabel 10, dapat dioperasikan dengan baik untuk mensuplai tegangan ke semua beban.

- Tabel 10. Hasil Pengujian Modul Catu Daya Beban Keseluruhan

\begin{tabular}{ccc}
\hline No. & $\begin{array}{c}\text { Tegangan Output pada } \\
\text { Tegangan 5 V (Volt) }\end{array}$ & $\begin{array}{c}\text { Tegangan Output pada } \\
\text { Tegangan 12 V (Volt) }\end{array}$ \\
\hline 1. & 4.81 & 11.96 \\
2. & 4.82 & 11.95 \\
3. & 4.82 & 11.95 \\
4. & 4.81 & 11.98 \\
5. & 4.81 & 11.95 \\
\hline Rata-rata & 4.81 & 11.96 \\
\hline
\end{tabular}

\section{Pengujian dan Analisis Sistem}

Pengujian sistem vertikultur dapat dilakukan pada ruangan terbuka dengan cahaya matahari pagi hingga malam hari. Cahaya yang diterima oleh sensor LDR mempengaruhi perubahan gerak vertikultur tiap jam. Berdasarkan hasil pengujian pada Tabel 9 dan Tabel 10, diperoleh sudut dari posisi vertikultur dalam kondisi terang (tiap jam) dan kondisi gelap. Dari pagi hingga malam hari, matahari dalam kondisi terang menunjukkan vertikultur bergerak menghadap cahaya matahari. Vertikultur bergerak dalam kondisi terang berdasarkan arah gerak matahari. Kondisi gelap (malam hari) atau dalam kondisi mendung vertikultur bergerak keposisi semula yaitu ke sudut $90^{\circ}$. Hasil pengujian tersebut menunjukkan sistem vertikultur memenuhi tujuan agar tanaman dapat menerima cahaya matahari secara merata.

Pengujian kedua dilakukan dengan beban yang diikatkan pada limit swicth sebagai batas minimum larutan nutrisi. Batas minimum yang telah ditentukan dapat mencegah kerusakan pada pompa air akibat dari kekurangan persediaan larutan nutrisi di dalam tangki. Persediaan larutan nutrisi dalam tangki dapat berkurang karena nutrisi yang dialirkan melalui pompa air akan diserap oleh akar tananam. Pengujian dilakukan apabila persediaan larutan nutrisi masih diatas batas minimum maka beban akan terampung sehingga menunjukkan limit switch tidak bekerja atau dalam keadaan off. Sedangkan, persediaan larutan nutisi telah melewati batas yang telah ditentukan maka beban dapat menekan limit swicth sehingga LED dan buzzer akan hidup sebagai indikator informasi. Berdasarkan hasil pengujian seperti pada Tabel 4.11, LED dan buzzer akan menyala apabila ketersediaan larutan nutrisi tidak terpenuhi. 
- Tabel 11. Hasil Pengujian Gerak Vertikultur Kondisi Terang

\begin{tabular}{|c|c|c|c|c|}
\hline \multirow{2}{*}{ Waktu (WIB) } & \multirow{2}{*}{ Arah Gerak } & Sudut Posisi & \multicolumn{2}{|c|}{ Limit Switch } \\
\hline & & Vertikultur $\left(^{\circ}\right)$ & Timur & Barat \\
\hline 08.00 & Barat & 100 & Off & Off \\
\hline 09.00 & Barat & 105 & Off & Off \\
\hline 10.00 & Barat & 115 & Off & Off \\
\hline 11.00 & Barat & 125 & Off & Off \\
\hline 12.00 & Barat & 135 & Off & On \\
\hline 13.00 & Barat & 135 & Off & On \\
\hline 14.00 & Timur & 45 & On & Of \\
\hline 15.00 & Timur & 45 & On & Off \\
\hline 16.00 & Timur & 58 & Off & Off \\
\hline 18.00 & Timur & 77 & Off & Off \\
\hline
\end{tabular}

- Tabel 12. Hasil Pengujian Gerak Vertikultur Kondisi Gelap

\begin{tabular}{ccccc}
\hline \multirow{2}{*}{ Kondisi } & \multirow{2}{*}{ Arah Gerak } & \multicolumn{2}{c}{ Sudut Posisi } & \multicolumn{2}{c}{ Limit Switch } \\
& Vertikultur $\left({ }^{\circ}\right)$ & Timur & Barat \\
\hline Mendung & Tengah & 90 & Off & Off \\
\hline - & Tabel 13. Hasil Pengujian Ketersediaan Larutan Nutrisi \\
\hline Batas Ketersediaan Larutan Nutrisi & Limit Switch & LED dan Buzzer \\
\hline Tidak Terpenuhi & 0 & Tidak Menyala \\
Terpenuhi & 1 & Menyala \\
\hline
\end{tabular}

\section{KESIMPULAN}

Kesimpulan yang diperoleh dari rancangan sistem vertikultur metode NFT dengan pencahayaan matahari secara merata dapat menghasilkan pertumbuhan tanaman selada dengan rata-rata tumbuh tinggi tanaman $2 \mathrm{~mm}$, lebar daun $2 \mathrm{~mm}$ dan daun berwarna hijau. Berdasarkan hasil pengujian pergerakkan sistem vertikultur yang dirancang dapat mengikuti perubahan arah gerak dari matahari dalam kondisi terang dan gelap. Berdasarkan hasil pengujian metode NFT dengan ketinggian lapisan larutan nutrisi dapat bekerja pada ketinggian $3 \mathrm{~mm}$ sampai 4 $\mathrm{mm}$. Hasil pengujian sistem dengan metode NFT dapat bekerja dengan spesifikasi dari rancangan. Pada perancangan selanjutnya dapat dilakukan dengan metode hidroponik lainnya, misalnya Drain Flood Technique (DFT) dan dapat menggunakan bentuk teknik vertikultur yang berbeda, dapat menggunakan talang air sebagai pengganti pipa PVC serta sensor LDR dapat digunakan sebagai input ADC dari mikrokontroler, agar tegangan referensi dapat diaturoleh mikrokontroler.

\section{DAFTAR PUSTAKA}

[1] My Trubus, Hidroponik Praktis. Jakarta : PT Trubus Swadaya, Oktober 2014, p.70, 73.

[2] Syarul, PemrogramanMikrokontroler AVR Bahasa Assembly dan C, Bandung: Informatika Bandung, 2014, p. 348

[3] Suraidi, S.T, M.T. dan A. Wendy, S.T, M.M., Petunjuk Praktikum Elektronika Dasar Universitas Tarumanagara, Edisi Genap 2008/2009.

[4] R. Boylestaddan L. Nashelsky, Electronic Device And Circuit Theory, $6^{\text {th }}$ ed. New Jersey:Practice-Hall International, INC., 1996. 